\title{
Mechanical Properties Test and Strength Prediction on Basalt Fiber Reinforced Recycled Concrete
}

\author{
Min Huang $(\mathbb{D}$, Yuru Zhao, Haonan Wang, and Shihao Lin \\ School of Civil Engineering, Henan University of Engineering, Zhengzhou 451191, China \\ Correspondence should be addressed to Min Huang; huangmin_2006@163.com
}

Received 20 October 2020; Revised 3 February 2021; Accepted 10 March 2021; Published 17 March 2021

Academic Editor: Tayfun Dede

Copyright (C) 2021 Min Huang et al. This is an open access article distributed under the Creative Commons Attribution License, which permits unrestricted use, distribution, and reproduction in any medium, provided the original work is properly cited.

In order to study the mechanical properties of basalt fiber reinforced recycled concrete (BFRRC), nine groups of tests are designed with three different replacement rates of recycled aggregates $(40 \%, 70 \%$, and $100 \%)$ and volume fraction of basalt fibers $(0.1 \%$, $0.2 \%$, and $0.3 \%)$. Another group of tests on ordinary concrete without fiber and recycled aggregate is used as comparison. The workability, cubic compressive strength, splitting tensile strength, and flexural strength of BFRRC are tested and analyzed. The effects of fiber content and recycled aggregate replacement ratio on the mechanical properties of concrete are studied. The strength development of fiber reinforced recycled concrete is predicted by using convolution neural network theory. The test results show that the fluidity of concrete mixtures decreases, while the cohesion and water retention are better than ordinary concrete with the increase of replacement ratio of recycled coarse aggregate and basalt fiber content. The compressive and flexural strength of recycled concrete first decrease and then increase slightly, while the splitting tensile strength of recycled concrete continue to decrease with the increase of replacement ratio of recycled aggregate. The flexural strength and splitting tensile strength of recycled concrete are obviously improved after adding basalt fiber, while the compressive strength increases first and then decreases with the increase of fiber content. A convolution neural network model for predicting the strength of basalt fiber reinforced recycled concrete is established. The predicted results are very close to the measured values and can be used as reference for the mix ratio of basalt fiber reinforced recycled concrete.

\section{Introduction}

With the large-scale construction of infrastructure, the lack of natural sand and aggregate has gradually become a common dilemma in civil engineering. On the other hand, due to urban demolition and reconstruction, a large amount of construction waste is generated. At present, the total amount of construction waste produced in China is about 1.55 billion to 2.40 billion tons every year, among which the content of concrete waste is more than $50 \%$. Currently, landfill or stacking is the main method for disposing concrete waste, and the recycling rate of concrete waste is less than 5\% [1]. Therefore, recycled concrete using concrete waste as aggregate is of great significance to the treatment of construction waste in urban development [2]. Xiao et al. [3] carried out relevant experimental research on the cube compressive strength, cube splitting tensile strength, and flexural strength of recycled concrete and revealed the change rule and influence mechanism of mechanical properties of recycled concrete under the influence of substitution rate and water cement ratio. Bao et al. [4] carried out four kinds of axial compressive stress levels ( 0 , $0.3 \mathrm{fc}, 0.5 \mathrm{fc}$, and $0.7 \mathrm{fc}$ ) after repeated loading with different substitution rate $(0,30 \%, 50 \%$, and $100 \%)$, which revealed the influence of stress level and aggregate substitution rate on capillary water absorption performance of recycled concrete. The literature [5-8] showed that if the recycled concrete is designed correctly and reasonably, its compressive strength can satisfy the requirement of the general engineering strength. The literature [9-11] showed that the contraction of recycled concrete is larger than ordinary concrete for the low apparent density and bulk density of recycled aggregates, higher silt content, and impurity. The literature [12-14] showed that the compressive strength of 
recycled concrete was not significantly different from that of ordinary concrete, but its flexural strength and tensile strength decreased significantly. The literature [15-17] showed that the permeability of recycled concrete is higher than that of ordinary concrete. The above defects limit the application of recycled concrete.

As a kind of inorganic fiber material with high strength and corrosion resistance, basalt fiber can effectively improve the tensile and flexural resistance of concrete [18-20] and improve the durability of concrete $[21,22]$. At present, some achievements have been gotten about the application of basalt fiber in ordinary concrete, but the research seems very inadequate for recycled concrete. Basalt fiber can improve the microstructure of recycled concrete and improve the compressive strength and tensile strength of recycled concrete [23-26]. The results of orthogonal test show that the content of basalt fiber and the replacement rate of recycled aggregate have important influence on the strength of recycled concrete $[27,28]$. The mechanical properties of recycled concrete can be improved by mixing basalt fiber and nano silica $[29,30]$. Basalt fiber and rubber particles can improve the deformation performance of recycled concrete [31]. Basalt fiber can effectively improve the bearing capacity of recycled concrete beams [32].

Artificial neural network is a model that has developed rapidly since the 1940s. It is a new technology of neural activity of anthropomorphic brain, which is suitable for processing the calculation model of complex nonlinear relationship. The artificial neural network can be used to build any input-output network [33]. At present, neural network technology has been widely used in the quality detection of concrete and has achieved certain results [34-36]. But the application of convolution neural network with deep learning in the prediction of concrete strength is relatively few [37]. On the basis of previous studies, this paper intends to use convolution neural network technology to predict the strength of basalt fiber reinforced recycled concrete. By studying the influence of different fiber content and different replacement rate of recycled coarse aggregate on the cube compressive strength, splitting tensile strength, and flexural strength of recycled concrete, the influence of basalt fiber content and replacement rate of recycled coarse aggregate on the mechanical properties of concrete is obtained. At last, one convolution neural network method $[37,38]$ is used to train and predict the strength of basalt fiber reinforced recycled concrete.

\section{Test Design and Method}

2.1. Raw Material Selection. $\mathrm{P} \bullet \mathrm{O} 42.5$ cement is adopted for cement (C) with a specific surface area of $380 \mathrm{~m}^{2} / \mathrm{kg}$. Its main performance indexes are shown in Table 1. River sand is used for fine aggregate (S) with a fineness modulus of 2.38 and an apparent density of $2530 \mathrm{~kg} / \mathrm{m}^{3}$. Natural coarse aggregate (NCA) is $5 \sim 20 \mathrm{~mm}$ continuously graded limestone gravel. Recycled coarse aggregate (RCA) is taken from the abandoned concrete after the demolition of an office building. The strength grade of RCA is C35, which is $5 \sim 20 \mathrm{~mm}$ gravel after crushing and sifting. The main properties of the two kinds of coarse aggregate are shown in Table 2. The basalt fiber is $12 \mathrm{~mm}$ long fiber produced by Zhengzhou Dengdian Basalt Fiber Limited Company, whose physical and mechanical properties are shown in Table 3. The fiber is shown in Figure 1. Superplasticizer (SP) is a polycarboxylic acid superplasticizer with a water reduction rate of $18 \%$.

2.2. Mix Proportion. According to the difference of fiber content and replacement rate of recycled coarse aggregate, a total of 10 groups of tests are designed. The content of basalt fiber shall be determined according to the volume fraction of concrete $0.1 \%, 0.2 \%$, and $0.3 \%$. The specific dosage of mixing ratio of each group is shown in Table 4. NC represents ordinary concrete, which is used as the test reference group. BFRRC represents basalt fiber reinforced recycled concrete; 40, 70, and 100 represent mass substitution percentage of recycled aggregate; $0.1,0.2$, and 0.3 represent basalt fiber volume percentage.

2.3. Specimen Forming in Test. Concrete compressive strength and splitting tensile strength are measured by cube standard blocks with a size of $150 \mathrm{~mm} \times 150 \mathrm{~mm} \times 150 \mathrm{~mm}$. The flexural strength of concrete is a nonstandard prism block with a size of $100 \mathrm{~mm} \times 100 \mathrm{~mm} \times 400 \mathrm{~mm}$. The concrete strength test blocks are made in two groups, one for strength test and the other for comparison with the prediction results of convolutional neural network.

In order to disperse basalt fiber evenly in the concrete, coarse aggregate is first added in the mixing pot, and then cement and fine aggregate are added. Water and basalt fiber are added slowly as the concrete is stirred, and the stirring time is no less than four minutes. The specimen is vibrated and formed by a concrete vibration table, which is inserted and compacted with steel bar, and finally is smoothed and formed by a spatula. The specimen is placed in an indoor maintenance room at $20^{\circ} \mathrm{C}$ for one day and one night. After the mold was removed, the specimen is placed in a standard constant temperature and humidity curing box for 28 days.

The typical concrete specimens for test are shown in Figures 2 and 3.

\section{Test Results and Analysis}

3.1. Workability Analysis of BFRRC. The workability of concrete mixture is an important working property of concrete. Good workability is conducive to the mixing transportation and construction of concrete and is an important parameter of concrete mix ratio design. Figure 4 shows the change of slump value of recycled concrete mixture with the increase of replacement rate of recycled coarse aggregate under different fiber dosage.

From Figure 4, we can get the following results.

(1) Under three different fiber contents, slump of the mixture decreases with the increase of replacement rate of recycled coarse aggregate, and its values are all less than the slump of the mixture of the reference group $(190 \mathrm{~mm})$. When the fiber content is $0.1 \%$, the 
TABLE 1: Measured properties of $\mathrm{P} \bullet \mathrm{O} 42.5$ cement.

\begin{tabular}{|c|c|c|c|c|c|c|c|c|}
\hline \multirow[t]{2}{*}{ Pilot project } & \multirow[t]{2}{*}{ Stability } & \multirow[t]{2}{*}{$\begin{array}{c}\text { Water usage for } \\
\text { standard consistency (\%) }\end{array}$} & \multicolumn{2}{|c|}{ Setting time $(\min )$} & \multicolumn{2}{|c|}{$\begin{array}{l}\text { Compressive } \\
\text { strength } \\
(\mathrm{MPa})\end{array}$} & \multicolumn{2}{|c|}{$\begin{array}{c}\text { Flexural } \\
\text { strength } \\
(\mathrm{MPa})\end{array}$} \\
\hline & & & Initial setting & Final setting & $3 \mathrm{~d}$ & $28 \mathrm{~d}$ & $3 \mathrm{~d}$ & $28 \mathrm{~d}$ \\
\hline Test results & Qualified & 26.6 & 175 & 230 & 24.6 & 47.8 & 5.1 & 8.0 \\
\hline
\end{tabular}

TABLE 2: Comparison of properties between natural coarse aggregate and recycled coarse aggregate.

\begin{tabular}{lcc}
\hline Project & Natural aggregate & Recycled aggregates \\
\hline Apparent density $\left(\mathrm{kg} / \mathrm{m}^{3}\right)$ & 2630 & 2536 \\
Packing density $\left(\mathrm{kg} / \mathrm{m}^{3}\right)$ & 1458 & 1319 \\
Bibulous rate $(\%)$ & 1.3 & 5.8 \\
Void fraction (\%) & 45 & 48 \\
Crush indicators (\%) & 9 & 15 \\
Needle flake particle content (\%) & 4.5 & 2 \\
\hline
\end{tabular}

TABle 3: Physical and mechanical properties of basalt fibers.

\begin{tabular}{lcccccc}
\hline Project & Linear density (tex) & Moisture content (\%) & Tensile strength (MPa) & $\begin{array}{c}\text { Modulus of } \\
\text { elasticity }(\mathrm{GPa})\end{array}$ & $\begin{array}{c}\text { Elongation at } \\
\text { break }(\%)\end{array}$ & $\begin{array}{c}\text { Apparent } \\
\text { density }\left(\mathrm{kg} / \mathrm{m}^{3}\right)\end{array}$ \\
\hline Measured results & 408 & 0.1 & 2392 & 71 & 2.9 & 2650 \\
\hline
\end{tabular}

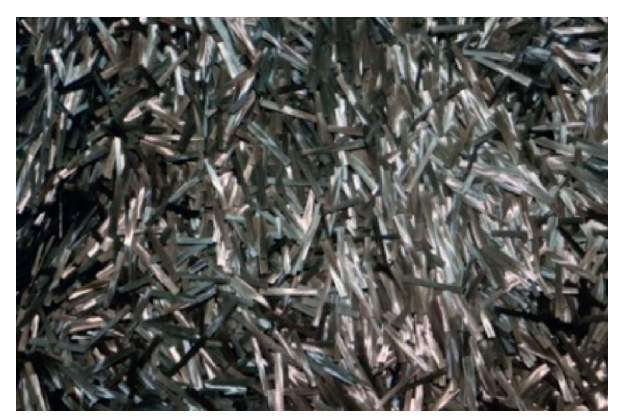

Figure 1: Basalt fiber.

TABLE 4: Mix proportion design in test.

\begin{tabular}{lcccccccc}
\hline \multirow{2}{*}{ Serial number } & Test code & Cement $(\mathrm{kg})$ & $\begin{array}{c}\text { River } \\
\text { sand }(\mathrm{kg})\end{array}$ & $\begin{array}{c}\text { Natural } \\
\text { stone }(\mathrm{kg})\end{array}$ & $\begin{array}{c}\text { Regeneration } \\
\text { gravel }(\mathrm{kg})\end{array}$ & Water $(\mathrm{kg})$ & $\begin{array}{c}\text { Basalt } \\
\text { fiber }(\mathrm{kg})\end{array}$ & Water-reducing agent $(\mathrm{kg})$ \\
\hline 1 & NC & 396 & 698 & 1196 & 0 & 158 & 0 & 7.9 \\
2 & BFRRC40-0.1 & 396 & 698 & 717.6 & 478.4 & 158 & 2.65 & 7.9 \\
3 & BFRRC40-0.2 & 396 & 698 & 717.6 & 478.4 & 158 & 2.65 & 7.9 \\
4 & BFRRC40-0.3 & 396 & 698 & 717.6 & 478.4 & 158 & 2.65 & 7.9 \\
5 & BFRRC70-0.1 & 396 & 698 & 358.8 & 837.2 & 158 & 5.3 & 7.9 \\
6 & BFRRC70-0.2 & 396 & 698 & 358.8 & 837.2 & 158 & 5.3 & 7.9 \\
7 & BFRRC70-0.3 & 396 & 698 & 358.8 & 837.2 & 158 & 5.3 & 7.9 \\
8 & BFRRC100-0.1 & 396 & 698 & 0 & 1196 & 158 & 7.95 & 7.9 \\
9 & BFRRC100-0.2 & 396 & 698 & 0 & 1196 & 158 & 7.95 & 7.9 \\
10 & BFRRC100-0.3 & 396 & 698 & 0 & 1196 & 158 & 7.95 & \\
\hline
\end{tabular}




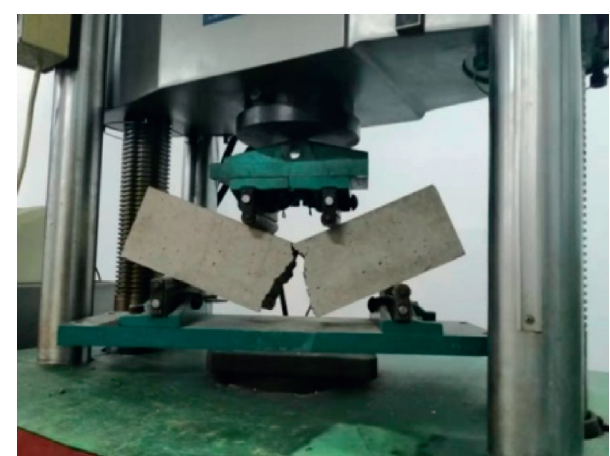

Figure 2: Flexural test of concrete.

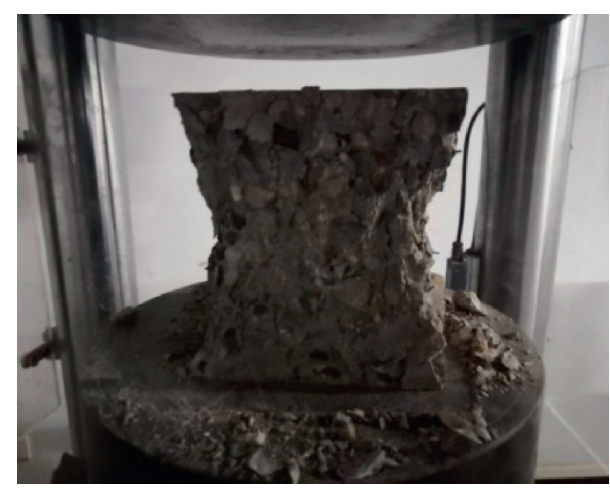

Figure 3: Compression test of concretes.

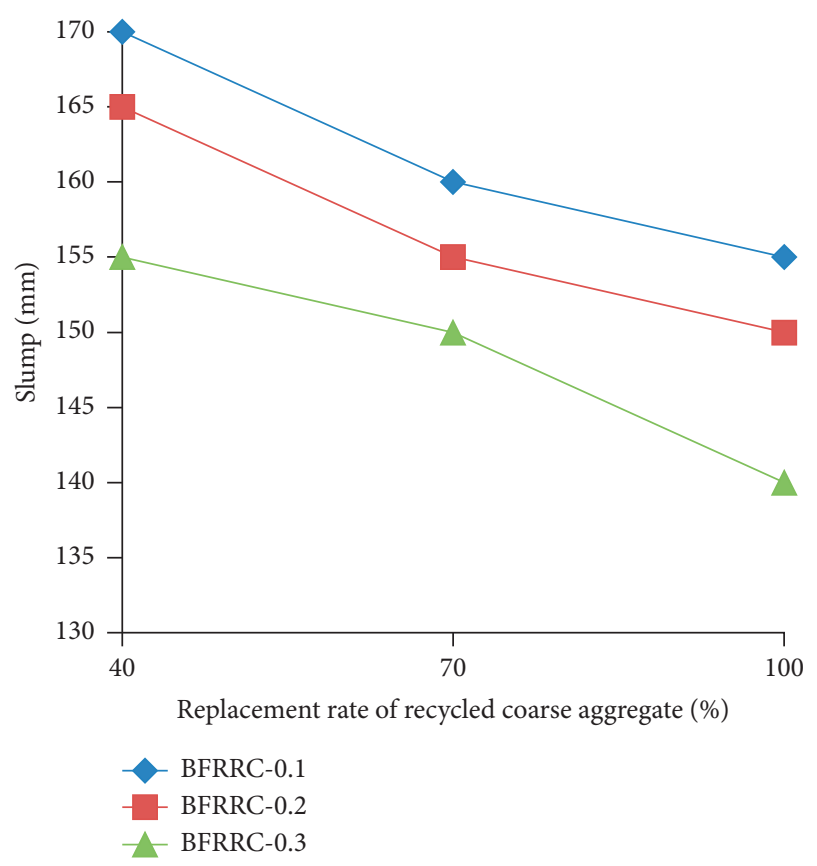

Figure 4: Slump change curve of BFRRC.

slump of recycled concrete decreases from $170 \mathrm{~mm}$ to $160 \mathrm{~mm}$ with the increase of replacement rate of recycled coarse aggregate. When the fiber content is
$0.2 \%$, the corresponding slump decreases from $165 \mathrm{~mm}$ to $155 \mathrm{~mm}$. When the fiber content is $0.3 \%$, the corresponding slump decreases from $155 \mathrm{~mm}$ to $140 \mathrm{~mm}$.

(2) The higher the fiber content is, the lower the overall slump value is. When the fiber content is $0.3 \%$ and the replacement rate of recycled coarse aggregate is $100 \%$, the slump of the mixture is the lowest, only $140 \mathrm{~mm}$, and the loss value for slump is $26.3 \%$ compared with the reference group. The main reason for the loss of slump of recycled basalt fiber concrete is that the wool pores of recycled coarse aggregate are more than natural aggregate, which lead to a higher water absorption rate, and it contains a certain mortar bonding layer, which reduces the free water volume of recycled concrete and causes the slump loss of mixing materials. Because of its high tensile strength and good toughness, basalt fiber can effectively improve the cohesive strength of concrete and reduce the measured slump of fiber concrete.

Although the slump of the recycled concrete mixture of basalt fiber has a certain loss, the basalt fiber dispersed in the concrete enhances the bond strength of the mixture, while the recycled aggregate has a higher water absorption rate, which has a stronger adsorption capacity of free water in the mixture. Therefore, the cohesion and water retention of the mixture of basalt fiber recycled concrete are better than those of ordinary concrete, and its fluidity is lower than that of ordinary concrete, which can be compensated by appropriately increasing the content of water-reducing agent or increasing sand rate.

3.2. Analysis of Compressive Strength of BFRRC. Figure 5 shows the variation of compressive strength of recycled concrete with the increase of replacement rate of recycled coarse aggregate under different fiber dosage.

From Figure 5, we can get the following conclusions:

(1) When the replacement of recycled coarse aggregate is $40 \%$, the compressive strength of concrete is the highest. It decreases first and then increases with the increase of replacement rate of recycled coarse aggregate. The reason is that the recycled coarse aggregate has higher porosity and lower strength, resulting in lower strength of recycled concrete. When the replacement rate is $100 \%$, the waterbinder ratio of recycled coarse aggregate is reduced due to its water absorption effect of porous structure, and its internal curing effect on recycled concrete and other factors enhance the compressive strength of recycled concrete. Taking $0.1 \%$ fiber content as an example, the cube compressive strength of recycled coarse aggregate with $40 \%$ replacement rate is $40.85 \mathrm{MPa}$, which decreases to $36.25 \mathrm{MPa}$ when the replacement rate is $70 \%$ and increases to $37.78 \mathrm{MPa}$ when the replacement rate is $100 \%$; the change rule of compressive strength under the other two fiber 


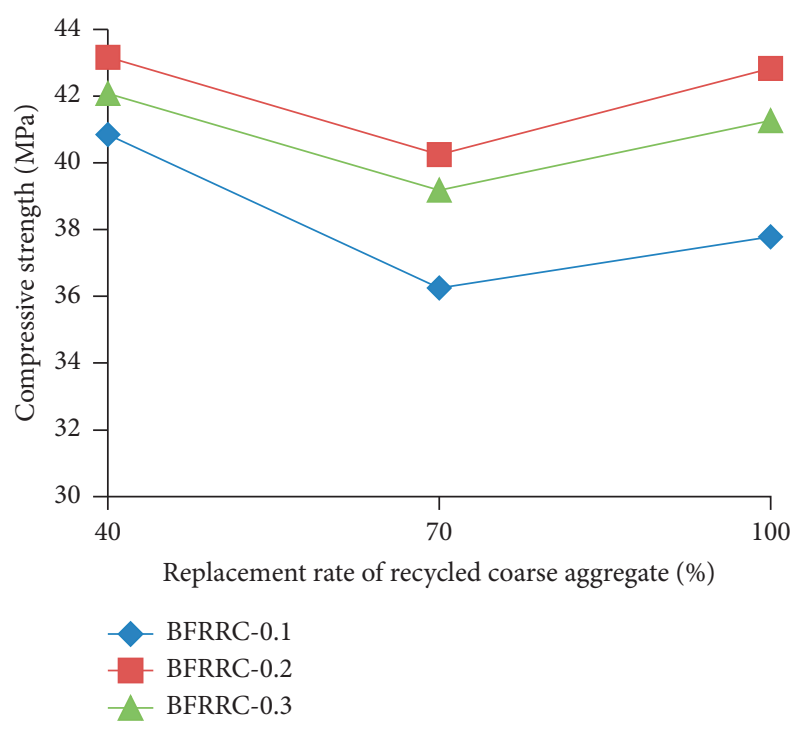

Figure 5: Compressive strength curve of BFRRC.

contents is similar, which will not be described in detail.

(2) With the same replacement rate of recycled coarse aggregate, the compressive strength of concrete cube first increases and then decreases with the increase of basalt fiber content, and the compressive strength is the highest when the fiber content is $0.2 \%$. Take the $40 \%$ replacement rate of recycled coarse aggregate as an example. When the fiber content is $0.1 \%$, the compressive strength of concrete is $40.85 \mathrm{MPa}$. When the fiber content is $0.2 \%$, the compressive strength of concrete is the highest, reaching $43.17 \mathrm{MPa}$. The compressive strength of concrete is $2.15 \%$ higher than that of the reference group $(42.26 \mathrm{MPa})$. When the fiber content increases to $0.3 \%$, the compressive strength of concrete decreases to $42.08 \mathrm{MPa}$. When the fiber content is between $0.1 \%$ and $0.2 \%$, the random distribution of fiber can improve the bonding strength of concrete and restrain the deformation of coagulation under load, so it can improve the compressive strength. When the content of fiber exceeds $0.2 \%$, the compressive strength of concrete will be reduced due to the possible bond defects between fiber and cement slurry and the agglomeration and cohesion phenomenon of basalt fiber caused by excessive content of fiber. Therefore, for the compressive strength of recycled concrete, the volume content of $0.2 \%$ basalt is the best content.

3.3. Analysis of Splitting Tensile Strength of BFRRC. Figure 6 shows the variation of splitting tensile strength of recycled concrete with the increase of replacement rate of recycled coarse aggregate under different fiber dosage.

From Figure 6, we can get the following conclusions.

(1) Under three different fiber contents, the splitting tensile strength of concrete is the highest when the

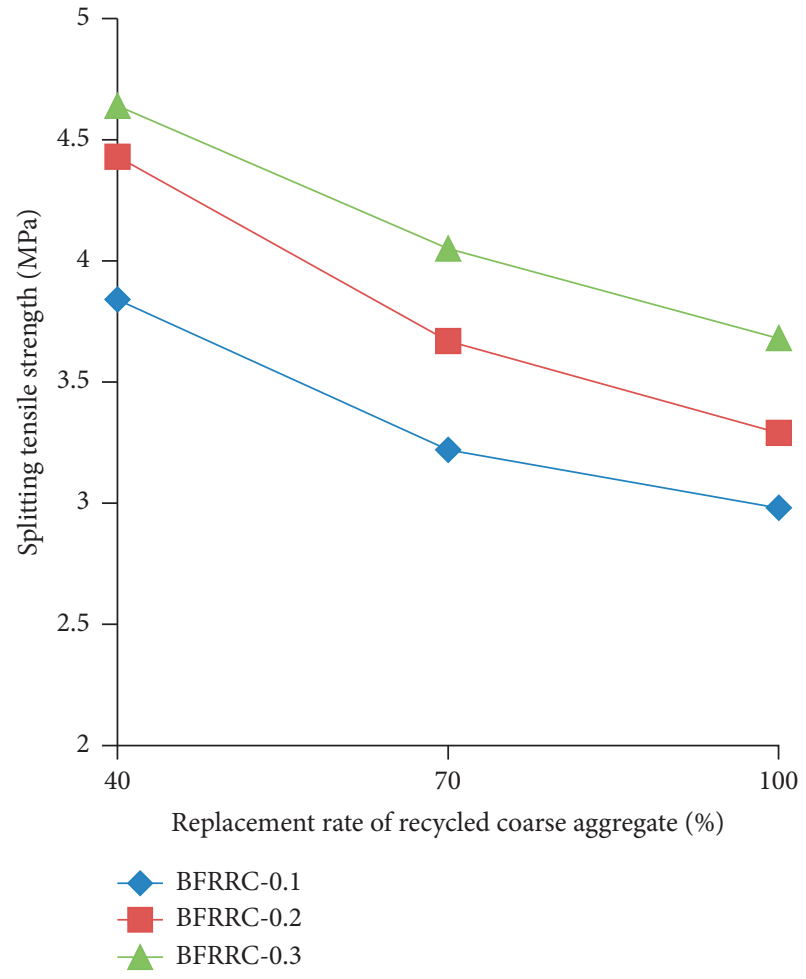

FIGURE 6: Curve of splitting tensile strength of BFRRC.

replacement of recycled coarse aggregate is $40 \%$, and it gradually decreases with the increase of recycled coarse aggregate substitute material. The reason is that the recycled coarse aggregate has higher porosity and lower strength, resulting in lower strength of recycled concrete. Recycled aggregate is often coated with old mortar layers, resulting in a weak interface at the junction with new cement slurry. When concrete is subjected to pressure load, the weak interface will show compaction and strengthening at the initial stage under the action of pressure load, with little influence on compressive strength. However, under the action of tensile stress, the weak interface will be destroyed sharply, reducing the tensile strength of concrete. Therefore, with the increase of replacement rate of recycled coarse aggregate, the splitting tensile strength of concrete decreases gradually. Taking $0.1 \%$ fiber content as an example, when the replacement rate of recycled coarse aggregate is $40 \%$, the splitting tensile strength of concrete is $3.84 \mathrm{MPa}$, and when the replacement rate is $70 \%$, it decreases to $3.22 \mathrm{MPa}$. When the replacement rate was $100 \%$, it was reduced to $2.98 \mathrm{MPa}$, which was $28.7 \%$ lower than $4.18 \mathrm{MPa}$ of the benchmark concrete. The changes of splitting tensile strength of the other two fiber contents are similar.

(2) With the same replacement rate of recycled coarse aggregate, the splitting tensile strength of concrete increases with the increase of basalt fiber content. Take the $40 \%$ replacement rate of recycled coarse 
aggregate as an example. When the fiber content is $0.1 \%$, the splitting tensile strength of concrete is $3.84 \mathrm{MPa}$. When the fiber content is $0.2 \%$, the splitting tensile strength increases to $4.43 \mathrm{MPa}$, which exceeds the concrete strength of the reference group, and the reinforcement proportion is $5.98 \%$. When the fiber content is increased to $0.3 \%$, the splitting tensile strength increases to $4.64 \mathrm{MPa}$, which is $11 \%$ higher than the benchmark concrete. The test results show that the basalt fiber content has an obvious enhancement effect on the splitting tensile strength of recycled concrete. This is because concrete tensile strength is very low; under the action of tensile stress, it is easy to produce cracks. Basalt fiber has high tensile strength, and its three-dimensional random distribution in concrete effectively inhibits and restricts the development of concrete cracks. The higher the tensile strength of the fiber and the fiber content are, the stronger the restraint effect on the cracks formed by the tensile stress is, and then the higher the splitting tensile strength of concrete is.

3.4. Analysis of Splitting Flexural Strength of BFRRC. Figure 7 shows the variation of the flexural strength of recycled concrete with different fiber content as the replacement rate of recycled coarse aggregate increases.

From Figure 7, we can get the following conclusions.

(1) Under three different fiber contents, the flexural strength of concrete with $40 \%$ recycled aggregate substitute is the largest, and the flexural strength of concrete with $70 \%$ recycled aggregate substitute is the lowest. The flexural strength of concrete with 100\% recycled aggregate substitute has certain increase compared with $70 \%$ substitute. The reason is that the recycled coarse aggregate has higher porosity and lower strength, and the old mortar layer around the surface of the recycled coarse aggregate often combines with the new cement slurry to form a weak interface, which is easy to be destroyed under flexural stress, resulting in the decline in the flexural strength of the recycled concrete. However, when the replacement rate increases to $100 \%$, the actual water-binder ratio of concrete is reduced due to the porous structure of recycled aggregate, and the actual strength of concrete is improved. Moreover, the micropore water contained in this kind of porous structure has a certain internal curing effect on the recycled concrete, which is beneficial to the strength growth of the recycled concrete in the later stage. Taking the fiber content of $0.1 \%$ as an example, the flexural strength of concrete with a replacement rate of $40 \%$ of recycled coarse aggregate is $5.89 \mathrm{MPa}$. When the replacement rate is $70 \%$, the flexural strength drops to the lowest value of $4.56 \mathrm{MPa}$, which is $37.02 \%$ lower than the flexural strength of the base concrete $(7.24 \mathrm{MPa})$. When the replacement rate is $100 \%$, it increases to $4.83 \mathrm{MPa}$. The flexural strength of concrete with other two kinds of fiber content is similar to the fiber content of $0.1 \%$.

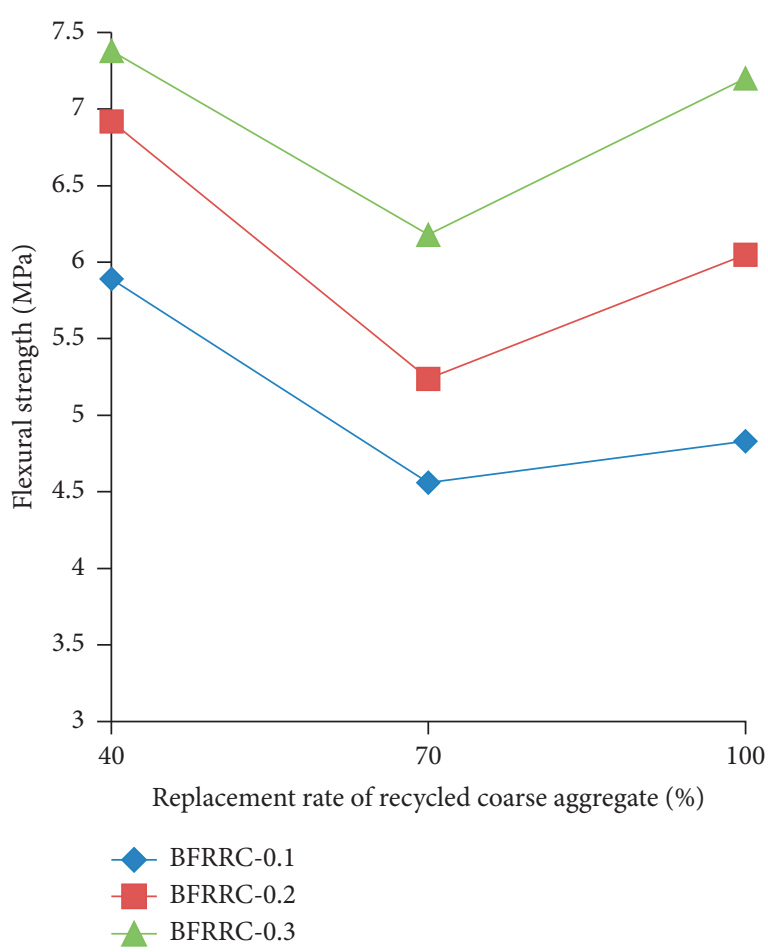

Figure 7: Flexural strength curve of BFRRC.

(2) With the same replacement rate of recycled coarse aggregate, the flexural strength of concrete also increases with the increase of basalt fiber content. Taking the replacement rate of recycled coarse aggregate at $40 \%$ as an example, when the fiber content is $0.1 \%$, the flexural strength of concrete is $5.89 \mathrm{MPa}$. When the fiber content is $0.2 \%$, the flexural strength increases to $6.92 \mathrm{MPa}$. When the fiber content is $0.3 \%$, the flexural strength of concrete increases to 7.38 $\mathrm{MPa}$, which has exceeded the flexural strength of the benchmark group of concrete, and the strengthening proportion is $1.93 \%$. The experimental results show that the content of basalt fiber has obvious enhancement effect on the flexural strength of recycled concrete. Due to the high tensile strength of basalt fiber, its random distribution in concrete effectively restricts the formation and development of bending and tension cracks of recycled concrete under the action of bending moment and improves the cracking resistance of recycled concrete. It makes up for the deficiency of low bending strength of recycled concrete. The higher the fiber content of recycled concrete is, the stronger the constraint effect on bending and tension cracks of recycled concrete under the action of bending moment is, then the higher the flexural strength of concrete is.

3.5. Summary of Section 3. It can be seen from the above that the mechanical properties of recycled aggregate concrete are generally not as good as ordinary concrete due to its low strength. After adding basalt fiber into recycled concrete, the 


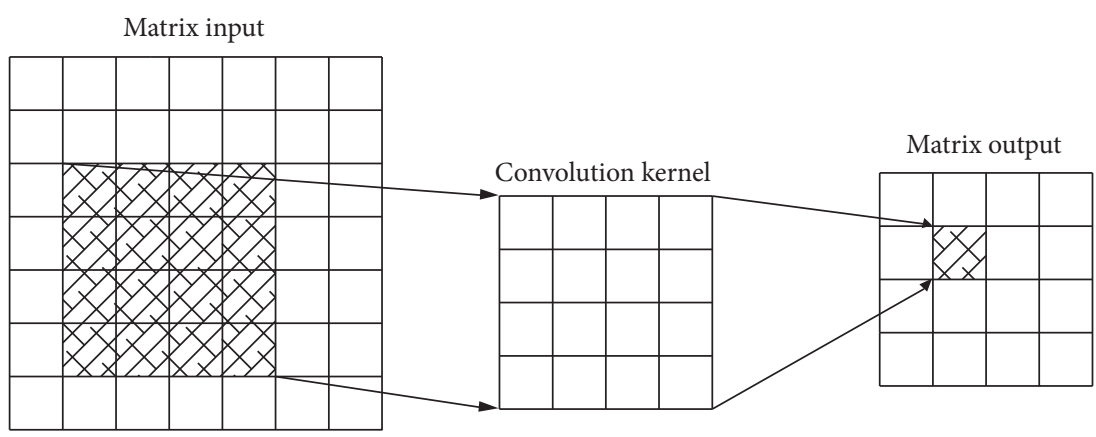

FIgURE 8: Schematic diagram of the convolution calculation principle.

TABLE 5: Comparison of strength predictive and measured values of BFRRC.

\begin{tabular}{|c|c|c|c|c|c|c|c|c|c|}
\hline \multirow{2}{*}{$\begin{array}{l}\text { Sample } \\
\text { name }\end{array}$} & \multicolumn{3}{|c|}{ Compressive strength (MPa) } & \multicolumn{3}{|c|}{ Splitting tensile strength $(\mathrm{MPa})$} & \multicolumn{3}{|c|}{ Flexural strength (MPa) } \\
\hline & $\begin{array}{c}\text { Measured } \\
\text { values }\end{array}$ & $\begin{array}{c}\text { Predictive } \\
\text { value }\end{array}$ & $\begin{array}{l}\text { Predictive } \\
\text { error (\%) }\end{array}$ & $\begin{array}{c}\text { Measured } \\
\text { values }\end{array}$ & $\begin{array}{l}\text { Predictive } \\
\text { value }\end{array}$ & $\begin{array}{c}\text { Prediction } \\
\text { error (\%) }\end{array}$ & $\begin{array}{c}\text { Measured } \\
\text { values }\end{array}$ & $\begin{array}{l}\text { Predictive } \\
\text { value }\end{array}$ & $\begin{array}{l}\text { Predictive } \\
\text { error }(\%)\end{array}$ \\
\hline $\begin{array}{l}\text { BFRRC40- } \\
0.1\end{array}$ & 40.24 & 40.65 & 1.02 & 3.79 & 3.85 & 1.58 & 5.61 & 5.77 & 2.85 \\
\hline $\begin{array}{l}\text { BFRRC40- } \\
0.2\end{array}$ & 43.28 & 43.12 & -0.37 & 4.92 & 5.01 & 1.83 & 6.84 & 6.99 & 2.19 \\
\hline $\begin{array}{l}\text { BFRRC40- } \\
0.3\end{array}$ & 42.74 & 42.9 & 0.37 & 4.76 & 4.8 & 0.84 & 7.54 & 7.42 & -1.59 \\
\hline $\begin{array}{l}\text { BFRRC70- } \\
0.1\end{array}$ & 36.95 & 36.12 & -2.25 & 3.44 & 3.39 & -1.45 & 4.78 & 4.81 & 0.63 \\
\hline $\begin{array}{l}\text { BFRRC70- } \\
0.2\end{array}$ & 41.24 & 41.63 & 0.95 & 3.55 & 3.64 & 2.54 & 5.46 & 5.53 & 1.28 \\
\hline $\begin{array}{l}\text { BFRRC70- } \\
0.3\end{array}$ & 38.87 & 39.25 & 0.98 & 4.2 & 4.31 & 2.62 & 6.02 & 6.17 & 2.49 \\
\hline $\begin{array}{l}\text { BFRRC100- } \\
0.1\end{array}$ & 38.43 & 37.97 & -1.20 & 3.07 & 3.14 & 2.28 & 5.02 & 4.88 & -2.79 \\
\hline $\begin{array}{l}\text { BFRRC100- } \\
0.2\end{array}$ & 43.29 & 43.02 & -0.62 & 3.43 & 3.34 & -2.62 & 5.98 & 6.12 & 2.34 \\
\hline $\begin{array}{l}\text { BFRRC100- } \\
0.3\end{array}$ & 41.17 & 41.69 & 1.26 & 3.85 & 3.92 & 1.82 & 7.34 & 7.29 & -0.68 \\
\hline
\end{tabular}

mechanical properties of recycled concrete are reinforced by basalt fiber, especially the tensile strength of concrete, due to the bridging and strengthening effect of fiber in concrete, which is consistent with the research conclusion of literature [18-32].

\section{Prediction of Strength of BFRRC Based on Neural Network}

4.1. Prediction Model of Convolutional Neural Network. From the above test results, it can be seen that the relationship between the strength of basalt fiber reinforced recycled concrete and the replacement rate of recycled coarse aggregate and fiber content is not linear. In order to predict its strength, convolutional neural network algorithm is introduced here for deep learning and prediction [39-41].

The principle of the algorithm is to learn layer by layer through the arrangement of multiple serial convolution layers and pooling layers and input the hidden layer through the kernel function. The hidden layer is mainly composed of alternate convolution layers and pooling layers. The process principle is shown in Figure 8, and the calculation formula is as follows:

$$
Y^{m}=f\left(\sum X^{s-1} \times K^{m}+B^{s}\right)
$$

where $Y$ is the convolution output, $s$ is the layer number of convolution, $X$ is the convolution input, $f$ is the activation function, $m$ is the convolution output dimension, $K$ are convolution kernels, and $B$ is bias.

In this paper, basalt fiber content and replacement rate of recycled coarse aggregate were selected as input variables and specimen strength as output parameters. The variables are trained and predicted by using the convolution neural network autonomous learning model, and the training predicted value of specimen strength is obtained. The model adopts three layers of network, namely, input layer, hidden layer, and output layer. The number of nodes in the input layer is 2, the number of nodes in the output layer is 1 , the number of nodes in the hidden layer is 7 , and the number of learning steps is 1200 . 
TABLE 6: Strength prediction results of BFRRC.

\begin{tabular}{lccc}
\hline Sample name & Compressive strength $(\mathrm{MPa})$ & Splitting tensile strength $(\mathrm{MPa})$ & Flexural strength $(\mathrm{MPa})$ \\
\hline BFRRC40-0.4 & 41.43 & 4.72 & 7.82 \\
BFRRC40-0.5 & 40.11 & 4.65 & 8.03 \\
BFRRC70-0.4 & 38.29 & 4.48 & 6.44 \\
BFRRC70-0.5 & 35.88 & 4.53 & 7.25 \\
BFRRC100-0.4 & 39.16 & 4.38 & 7.52 \\
BFRRC100-0.5 & 38.07 & 4.52 & 7.56 \\
\hline
\end{tabular}

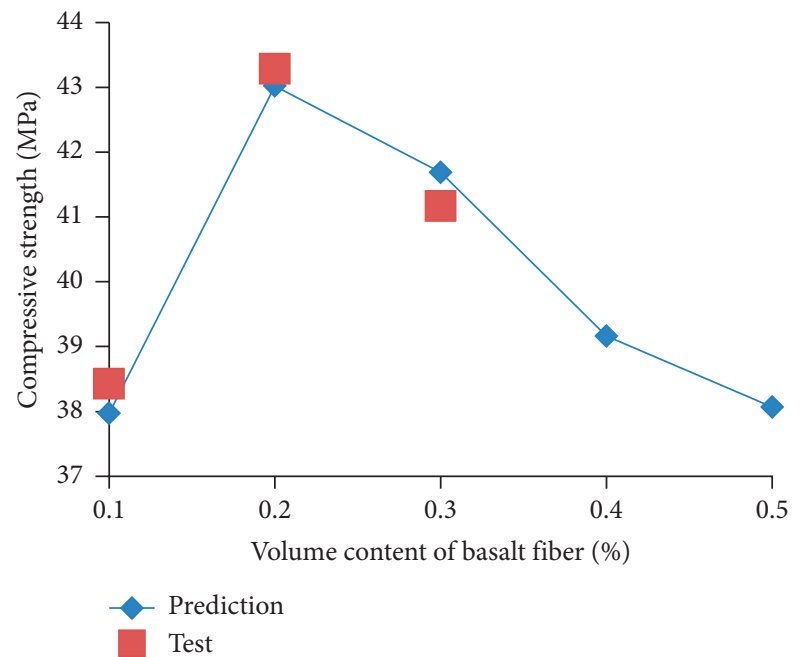

Figure 9: Variation of compressive strength of BFRRC.

4.2. Strength Prediction of BFRRC. Table 5 shows the comparison between the predicted and measured values of convolutional neural network training for strength indexes of recycled concrete under different fiber content and replacement rate of recycled coarse aggregate.

As can be seen from Table 5, the training prediction results of three strengths of basalt fiber reinforced recycled concrete through convolutional neural network are very close to the measured values, and the error is not more than $3 \%$, indicating that the method of convolutional neural network for concrete strength prediction is feasible. In order to further understand the strength development rule of recycled concrete with different basalt fiber content, the strength of recycled concrete with volume content of basalt fiber being $0.4 \%$ and $0.5 \%$, respectively, is predicted using convolutional neural network. The predicted calculation results are shown in Table 6.

In order to more vividly represent the predictive results of convolutional neural network, we can take the strength of basalt fiber reinforced recycled concrete when the replacement rate of recycled coarse aggregate is $100 \%$ as an example. The actual strength and predicted strength of concrete are expressed in the form of a broken line diagram, which is shown in Figures 9-11.

Based on the prediction of convolutional neural network of BFRRC and the measured strength of the specimen, it can be seen that when the basalt fiber content is $0.2 \%$, the compressive strength of the recycled concrete is the highest. After exceeding $0.2 \%$, it decreases gradually. The higher the
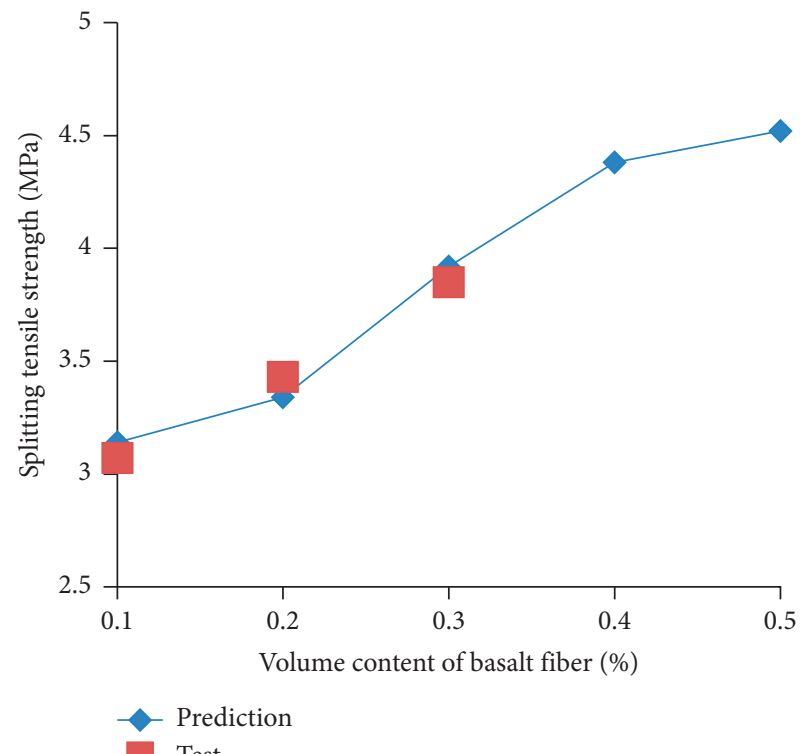

FIGURE 10: Variation of split tensile strength of BFRRC.

content of basalt fiber is, the higher the splitting tensile strength of the recycled concrete is, showing a trend of stable increase. The results indicate that the basalt fiber has an obvious enhancement effect on the tensile strength of the recycled concrete. For the flexural strength, it also increases gradually with the increase of fiber content. However, when the fiber content exceeds $0.3 \%$, the increase becomes smaller and smaller. The flexural strength of concrete with $0.5 \%$ fiber content is $7.56 \mathrm{MPa}$, which is only $3 \%$ higher than that of concrete $(7.34 \mathrm{MPa})$ with $0.3 \%$ fiber content. The reason for the above results is that with the increase of fiber content, it is not easy to disperse in concrete, and it is easy to form agglomerations, resulting in the continuous decline of concrete compressive strength. However, the tensile strength of basalt fiber is high while the tensile strength of recycled concrete is low. Therefore, the enhancement of the tensile strength of recycled concrete after the increase of fiber content counteracts the adverse effect of basalt fiber agglomeration. Therefore, the splitting tensile strength and flexural strength of BFRRC can be continuously enhanced with the increase of fiber content. However, for the flexural strength, since the overall value is higher than the splitting tensile strength, the marginal effect of increased fiber content on the strength of flexural strength becomes smaller and smaller after exceeding a certain range. Therefore, the flexural strength of BFRRC still increases after the fiber 


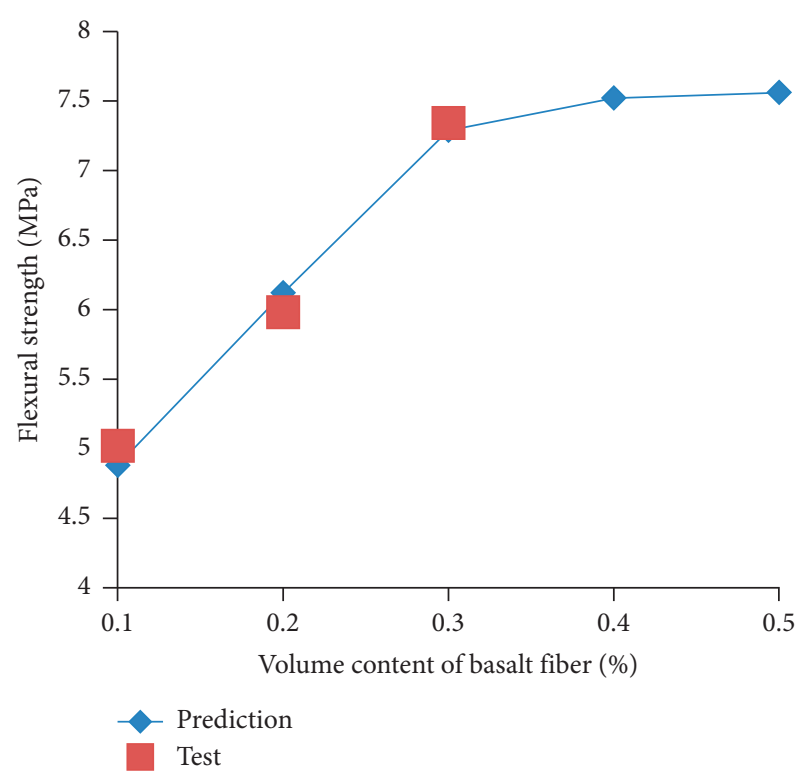

FIGURE 11: Variation of flexural strength of BFRRC.

content exceeds $0.3 \%$, but the strengthening effect becomes less and less obvious.

\section{Conclusion}

(1) The higher the replacement rate of recycled coarse aggregate and the larger the content of basalt fiber are, then the lower the fluidity of concrete mixture is. However, the cohesion and water retention of concrete are good.

(2) The compressive strength, splitting strength, and flexural strength of recycled concrete are lower than those of ordinary concrete. As the replacement rate of recycled coarse aggregate increases, the compressive strength and flexural strength of recycled concrete decrease first and then increase. When the replacement rate of recycled coarse aggregate is $70 \%$, its compressive strength and flexural strength are the lowest. The splitting tensile strength of recycled concrete continue to decrease with the increase of the replacement rate of recycled coarse aggregate.

(3) The split tensile strength and flexural strength of basalt fiber reinforced concrete are higher than those of non-fiber reinforced concrete. Its value increases with the increase of fiber content. With the increase of basalt fiber content, the compressive strength first increases and then decreases. The compressive strength is the greatest when the fiber volume content is $0.2 \%$.

(4) By adding basalt fiber, the defect of low strength of recycled concrete is effectively improved. The experimental results show that appropriate dosage basalt fiber reinforced concrete can meet the requirements of strength and workability of ordinary structural engineering.
(5) It is feasible to use convolution neural network to predict the strength of BFRRC. The predictive strength value is very close to the measured strength of concrete. It can be used as a reference for proportion design of basaltic fiber recycled concrete. Further neural network strength prediction shows that the compressive strength of fiber recycled concrete will continue to decrease after basalt fiber content exceeds $0.3 \%$, while its flexural strength and splitting strength will continue to increase.

\section{Data Availability}

The data used to support the findings of this study are available from the corresponding author upon request.

\section{Conflicts of Interest}

The authors declare that there are no conflicts of interest regarding the publication of this paper.

\section{Acknowledgments}

The authors gratefully ackowledge the financial support of Science and Technology Research Plan of Henan Province (no. 162102310403), Key Natural Science Research Projects of Henan Education Department (no. 12A560004), Zhengzhou Science and Technology Development Plan (no. 20130816), and Doctoral Fund Project of Henan University of Engineering (no. D2012008).

\section{References}

[1] H. Cheng, G. Liu, F. Yang et al., "Influence of recycled waste concrete aggregate and mineral admixtures on durability of GRC," Journal of Building Materials, vol. 21, no. 3, pp. 490-496+510, 2018.

[2] K. Xiao, Study on Properties and Modification of Recycled Concrete, Wuhan University of Technology, Wuhan, 2004.

[3] B. Xiao, X. An, R. Yang et al., "Experimental research on basic mechanical characterist ics of recycled aggregate concrete and influencing factors," Concrete, vol. 11, pp. 32-36+40, 2018.

[4] BaoS. Li et al., "Water absorption of recycled aggregate concrete after repeated axial compressive loading," Journal of Building Materials, vol. 22, no. 11, pp. 1-12, 2019.

[5] Z. Chen, C. Zhou, D. Xu et al., "Influence of aggregate type on mechanical behaviors of recycled aggregate concrete," Chinese Journal of Applied Mechanics, vol. 1, pp. 180-185, 2017.

[6] G. Fu, M. Zhou, and Pu Qi, "Research progress of performance of recycled coarse aggregate and recycled concrete," China Concrete and Cement Products, vol. 9, pp. 102-107, 2018.

[7] J. Li, J. Xiao, and Z. Sun, "Properties of recycled coarse aggregate and its influence on recycled concrete," Journal of Building Materials, vol. 7, no. 4, pp. 390-395, 2004.

[8] J. Sun and H. Jiang, "Study on properties of reclaimed coarse aggregate and its influence on properties of concrete," New Building Materials, vol. 1, pp. 30-32, 2009.

[9] R. Kurda, J. de Brito, and J. D. Silvestre, "Combined influence of recycled concrete aggregates and high contents of fly ash on concrete properties," Construction and Building Materials, vol. 157, pp. 554-572, 2017. 
[10] H. Liu and B. Yan, "Influence of amount and size of aggregate on drying shrinkage of concrete," Bulletin of the Chinese Ceramic Society, vol. 1, pp. 204-207, 2015.

[11] Z. Cui and J. Li, "Effect of coarse aggregate with different water absorption on strength and drying shrinkage of concrete," Bulletin of the Chinese Ceramic Society, vol. 8, pp. 2396-2399, 2016.

[12] L.-j. Xue, G.-1. Guo, and Y.-j. Lin, "Mechanical performance of recycled concrete based on waste glass fine aggregate," Journal of Shaanxi University of Technology (Natural Science Edition), vol. 35, no. 5, pp. 39-44, 2019.

[13] H. Shang, Y. Song, and L. Tan, "Experimental study on the performance of NC freeze-thaw cycle," China Concrete and Cement Products, vol. 2, pp. 9-11, 2005.

[14] S. Han, Q. Li, X. Zhang et al., "Influence of quality and substitution rate of recycled coarse aggregate on anti-freeze performance of recycled concrete," Periodical of Ocean University of China, vol. 1, pp. 96-104, 2017.

[15] H. Cheng, G. Liu, and P. Liu, "Mix optimizing experiments of recycled waste concrete aggregate GRC products," Recyclable Resources and Circular Economy, vol. 9, no. 11, pp. 28-33, 2016.

[16] J. Ying, Q. Meng, and J. Xiao, "Effect of CO2-modified recycled aggregate on compressive strength of concrete," Journal of Building Materials, vol. 20, no. 2, pp. 277-282, 2017.

[17] G. Peng, Y. Huang, and J. Zhang, "Influence of defects in recycled aggregate on mechanical properties of recycled aggregate concrete," Journal of Building Materials, vol. 15, no. 1, pp. $80-84,2012$.

[18] Y. Pan, C. Liang, Z. He et al., "Research progress on the chloride permeability of recycled aggregate concrete," Bulletin of the Chinese Ceramic Society, vol. 37, no. 2, pp. 501-507, 2018.

[19] J. Wang, Y. Ma, Y. Zhang et al., "Experimental research and analysis on mechanical properties of chopped basalt fiber reinforced concrete," Engineering Mechanics, vol. S1, pp. 99-102, 2014.

[20] C. Zhang, "Experimental research on mix proportion of basalt fiber reinforced concrete," China Concrete and Cement Products, vol. 3, pp. 48-50, 2018.

[21] J. Bi, J. Zhou, B. Chun et al., "Experimental study on properties of basalt fiber reinforced self-compacting concrete," New Building Materials, vol. 1, pp. 84-87, 2018.

[22] Z. ei, S. Yuan, J. Dong et al., "Experimental study on mechanical properties of basalt fiber reinforced recycled concrete after sulfate corrosio," China Concrete and Cement Products, vol. 11, pp. 59-64, 2018.

[23] T. Dong, W. Liao, J. Liu et al., "Influence of basalt fiber on mechanical properties of recycled aggregate concrete and numerical simulation"” Concrete, vol. 9, pp. 1-8, 2019.

[24] H. Dilbas and Ö. Çakır, "Influence of basalt fiber on physical and mechanical properties of treated recycled aggregate concrete," Construction and Building Materials, vol. 254, p. 254, 2020.

[25] S. Li and D. Ding, "Experimental study on basic mechanical properties of recycled basalt concrete," Heilongjiang Science, vol. 22, pp. 28-30+33, 2019.

[26] X. Quan, K. Liu, S. Wang et al., "Experimental study on basic mechanical properties of basalt fiber RAC," Concrete, vol. 6, pp. 47-50, 2019.

[27] M. Hung, Y. Zhao, J. Yuan et al., "Orthogonal test and strength prediction on basalt fiber reinforced recycled concrete," Journal of Henan Institute of Engineering (NATURAL SCIENCE EDITION), vol. 4, pp. 22-27, 2019.
[28] H. Zhou, A. Chen, X. Han et al., "Analysis of basic properties of basalt fiber reinforced rubber recycled concrete by orthogonal design," Concrete, vol. 11, pp. 74-77+82, 2019.

[29] Wang, P. Hughes, H. Niu et al., "A new method to improve the properties of recycled aggregate concrete: composite addition of basalt fiber and nano-silica," Journal of Cleaner Production, vol. 236, pp. 1-12, 2019.

[30] Y. Wang, H. Niu, and Y. Fan, "Compressive properties and microstructure of modified recycled concrete," Journal of China University of Mining and Technology, vol. 5, pp. 1012-1019, 2019.

[31] Chen, X. Han, M. Chen et al., "Mechanical and stress-strain behavior of basalt fiber reinforced rubberized recycled coarse aggregate concrete," Construction and Building Materials, vol. 260, pp. 1-11, 2020.

[32] S. Li, Y. Zhang, and W. Chen, "Bending performance of unbonded prestressed basalt fiber recycled concrete beams," Engineering Structures, vol. 221, pp. 1-9, 2020.

[33] Z. Lin, H. Tang, D. Li et al., "Prediction of the peak load capacity of RC columns by neural network," Structural Engineers, vol. 1, pp. 174-179, 2019.

[34] C. Wang, He Jia, S. Zhang et al., "Image based quantitative and efficient identification method for concrete surface cracks," Journal of Hydroelectric Engineering, vol. 9, pp. 1-11, 2019.

[35] C. Li, H. Luo, W. Wei et al., "Detection of concrete surface cracks and bugholes based on image," Journal of Civil Engineering and Management, vol. 12, pp. 118-123, 2020.

[36] S. Lei, H. Cao, and J. Kang, "Study on concrete surface crack recognition in complex scenario based on deep learning," Journal of Highway and Transportation Research and Development, vol. 12, pp. 80-88, 2020.

[37] W. Gao, "Influencing factors and deep learning predict ion model of compression strength of recycled concrete," Concrete, vol. 11, pp. 58-61+70, 2018.

[38] Y. Guo, Y. Liu, W. Wang et al., "Prediction of compressive strength of regenerated thermal insulation concrete based on BP neural network," Concrete, vol. 10, pp. 33-35, 2018.

[39] S. Zhou, W. Sheng, and S. He, "Prediction of chloride diffusion coefficient of high performance concrete based on depth learning in chloride environment," Concrete, vol. 7 , pp. 27-31, 2019.

[40] O. A. Hodhod and H. I. Ahmed, "Developing an artificial neural network model to evaluate chloride diffusivity in high performance concrete," Hbrc Journal, vol. 9, no. 1, pp. 15-21, 2013.

[41] I.-C. Yeh, "Modeling slump flow of concrete using secondorder regressions and artificial neural networks," Cement and Concrete Composites, vol. 29, no. 6, pp. 474-480, 2007. 